\title{
Where I Practice: On the Spaces of Family Medicine
}

\author{
William B. Ventres, MD, MA
}

In this essay, the author explores 3 distinct "spaces" that have helped him metaphorically map the nature of his work as a family physician. These "spaces" represent cultural, personal, and relational environments in which he has practiced over the course of $>30$ years since beginning medical school. They concern, respectively, the dominant culture of medicine, one core philosophy of family medicine (the biopsychosocialexistential model), and the development of strong therapeutic bonds with patients. The author presents this textual and graphic exploration of "space" in hopes that others might reflect on their work, examine how they approach it, and bring richness and renewed meaning to their work as family physicians. (J Am Board Fam Med 2015;28:841-844.)

Keywords: Cross-Cultural Care, Doctor-Patient Relations, Education, Ethics, Family Relations

This is a special period in the history of family medicine in the United States. Almost 50 years after its founding as an academic discipline, our professional organizations have introduced "Family Medicine for America's Health" as a well-timed examination of our collective identity and purpose. ${ }^{1}$ As a result, many family physicians are reevaluating their places in the health care arena. Some wonder what will become of our specialty and whether it will weather varied ongoing challenges, among them the politics surrounding the Patient Protection and Affordable Care Act, the changes triggered by electronic medical records, and the continued misrepresentation of family medicine's presence within academic institutions. ${ }^{2-4}$ Others are more encouraging about family medicine's future, buoyed by data that support expanding family medicine's role on the stage of medical care and learned

This article was externally peer reviewed.

Submitted 14 January 2015; revised 27 May 2015; accepted 5 June 2015.

From the Institute for Studies in History, Anthropology and Archeology, University of El Salvador, San Salvador, El Salvador; and the Department of Family Medicine, Oregon Health \& Science University, Portland, OR.

Funding: none.

Conflict of interest: none declared.

Corresponding author: William B. Ventres, MD, MA, Urbanización Buenos Aires III, Block H, Calle Los Maquilishuat, No. 3-A, San Salvador, El Salvador (E-mail: wventres@ gmail.com). insights as to the wisdom of a family medicine model for delivering rational health care services. ${ }^{5,6}$

As a family physician with over 25 years' experience in community-based practice, I have not been immune to harboring doubts about the future of family medicine-the cultural and political-economic power of the current biomedically focused, subspecialty-oriented, market-based care model is indeed a daunting force to contend with. Yet I remain optimistic about our future, especially when I appreciate the metaphoric "spaces" that have helped me map the nature of my work. These spaces have helped me provide, as I have been able, the kind of quality care that results from being my patients' personal physician.

In this essay I explore 3 distinct "spaces" that, over time, have come to frame my practice of family medicine. First, cultural space describes where I stand relative to the dominant values of medicine. Second, philosophical space expresses how I make sense of the clinical process as a generalist physician. Third, relational space spotlights the connection in between my patients and me; this "space" both illuminates important illness-related issues and is therapeutic in and of itself.

My purpose is not only to illustrate how such spaces have been vitally important for my professional growth but also to invite other family physicians to consider what "spaces" have helped them cultivate the healing presence that forms the foun- 
dation of our discipline. ${ }^{7-9}$ Knowing that each of us envisions and conducts our practices in ways slightly different from others, I encourage family physicians to use this consideration of spaces as a motivation for reflecting on how they can build, sustain, and enjoy their practices in times of rapid and unforeseeable change.

\section{Culture and Counterculture}

I entered medical school over 30 years ago. Although my early professional education focused on particularized biomedical knowledge, I quickly came to realize that people were at the center of physicians' work. I became frustrated by the supremacy of disease diagnosis over caring for patients. My residency in family medicine was an improvement over medical school; at least I could share my frustrations without fear of them being dismissed out of hand. Nonetheless, it too was heavily focused on specialty service rotations: family physician development by default, one rotational subspecialist building block placed on another, until it somehow added up.

During this time in my professional life, I was desperately seeking some path to attend to patients as persons. I dealt with my alienation by frequently recalling the words of an early mentor. Once, responding to my expressions of being on the fringe of conventional medical thinking, he said: "Stay there. There is a power on the edge that one cannot consider from perspectives closer to the center of things. On the edge exists an unimaginable freedom that others cannot even fathom." Still, it was not easy.

Later, I read Gayle Stephens's ${ }^{10}$ article, "Family Medicine as Counterculture." In it, Stephens-one of the founders of the family medicine movement-wrote that cultures of resistance always arise to question, if not reform, dominant cultures, all which lack insight into their limitations and failings because of their dominance. Biomedicine is one such hegemonic culture; family medicine was an early "counter" culture. Complementary and alternative medicine and palliative care are other, more recent versions. ${ }^{11,12}$

After several years in community-based practice I finally figured out how to practice comprehensive integral medicine and acknowledge my work as a family physician as a force to humanize medicine, in my own very little way. At this "space" at the edge, I modeled a vision distinctly different from what I had been taught and, at least for those few medical students who rotated through my office, worked to demonstrate family medicine as a cutting-edge inspiration for person-centered medical care. $^{13}$

\section{The Biopsychosocialexistential Model}

After residency I learned of George Engel's ${ }^{14,15}$ biopsychosocial model, just as it was just gaining traction as a descriptive framework for understanding how astute clinicians can attend to biological, psychological, and social issues. Upon adding a existential dimension (biopsychosocial-existential [BPSE] $),{ }^{16}$ I was better able to visualize and grasp the nature of my complex day-to-day tasks than I had previously been able to (based on the family life cycle orientation taught in training ${ }^{17}$ ).

Having become more cognizant of and more confident in my role as a family physician, I recognized a flip side to the BPSE model. For each of the BPSE elements, I recognized other, less obvious factors that influence health-factors that exist as shadow "spaces" to the BPSE model (and well outside the evidence-based mind-set that preferentially values quantifiable data over intuitive wisdom). ${ }^{18,19}$ These 4 paired shadow spaces are part and parcel of patient care in family medicine.

First, external physical environments affect internal biological functioning. While this relationship can be described as social determinants of health, ${ }^{20}$ I prefer to call it a social interdependency in health and illness: As a family physician I share some responsibility in my patients' worlds, one that can and help or hurt their overall health depending on how I approach my work with them. Second, part of this approach is determined by my own emotional awareness in light of patients' psychological distress. My therapeutic effectiveness is in large part influenced by whether I am open to hearing, reflecting on, and responding to my patients' illness narratives. ${ }^{21}$ Third, these stories arise not solely out of the social organization that places doctors and patients together in times of bodily dysfunction, but out of healing bonds built on nonjudgmental respect and a commitment to care, both in the moment and over extended periods of time. ${ }^{22}$ Fourth, while in some cases these healing relationships may include recognition of patients' spiritual beliefs, they all rely on nurturing what I call "little 
Figure 1. The space in between, where I do my best work as a family physician.

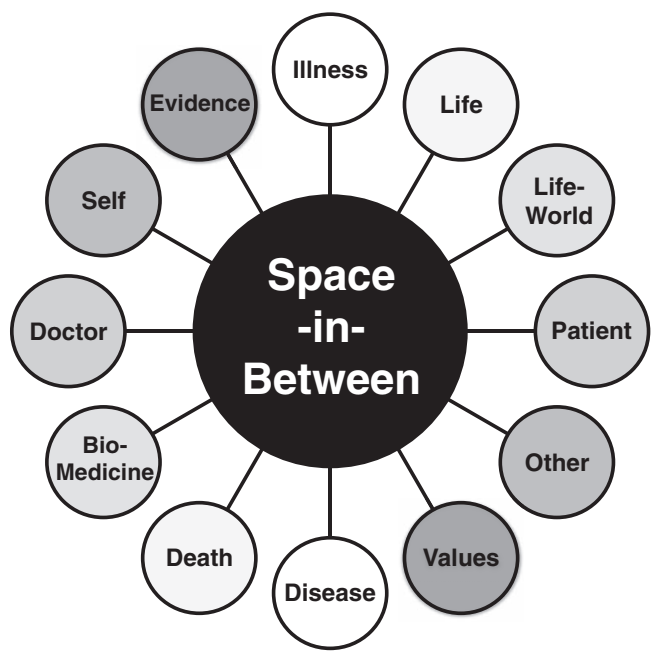

'f faith" ${ }^{23}$ : the power of hope, resilience, and acceptance in the face of disease, disability, andultimately-death. ${ }^{24}$

\section{The Space in Between}

As I have continued to mature professionally, happily recognizing my successes and hopefully learning from my mistakes, I have come to believe that I do my best work in the "space in between": in between medicine and people, in between illness and disease, in between life and death, in between cultures and families and all else that goes into encounters between my patients and me (Figure 1).

This "space in between" is challenging to conceptualize in that it is neither black nor white (nor truly defined by any one of the axes depicted in Figure 1). It is not quantifiable in any conventional sense and, even if, for a moment, it were, that moment would inevitably change, creating whole new realities to discover. It is a space born of differences between my patients and me, differences in knowledge, history, skill, and perspective. It is, as well, a function of my own ability to be self-aware at work, trying to be an authentic healer in a culture that pushes me to conform to norms of high-level production and superficial measures of quality. This space has helped me remember the reasons I became a family physician-putting patients first-at the same time I navigate the challenging currents of consumerism, information technology, and corporate dominance.
It is in this space in between that I create a shared presence with my patients, moments during clinical interactions that are immediately healing and resonate as therapeutic remembrances long afterward. ${ }^{25}$ I cannot create shared presence on my own, but I can invite participation. And I can be there, open to cultivating shared presence, when others need it for their own well-being. There is a sense of generosity in it all, for which I am immensely grateful: I am generous when I open doors to this space for others; I am a recipient of generosity when I walk through doors others open up for me.

\section{Further Reflections}

Surely, family medicine can be practiced without any consideration of "space." At a time when many educational, administrative, financial, and technological forces push us to attend less to patients and more to paperwork (albeit now digitized), it is tempting to do the job of medicine without doing the work of patient care. Something as basic as a SOAP note, especially one constructed using preprogrammed point-and-click computer forms, can be filled in-subjective, objective, assessment, and plan-almost without listening to a patient, performing a physical examination, considering diagnostic possibilities and probabilities, and creating a purposeful therapeutic strategy.

Some may describe their spaces differently, structuring them around other discrete dimensions. Where I see "space" they might imagine ethics, cultures, or even institutional structures. I have no qualms acknowledging these differences. My use of space helps to nurture and sustain my professional development; others may find alternative cognitive maps more helpful in guiding their reflections.

In addition, clinicians other than family physicians might complain that "space" applies to their practices, as well. They are correct. How I frame space arises out of my growth as a family physician, ${ }^{26}$ drawing from both the principles that gave birth to the discipline and the realities of my practice in community-based safety-net clinics. ${ }^{27,28}$

The bottom line is that these three "spaces" of practice have been, and continue to be, important both to my identity as a family physician and to my professional stance vis-à-vis patients. I encourage others to reflect on what "spaces" influence their work, so as to help bring richness and renewed meaning to their clinical endeavors. 
The author thanks Richard Frankel, PhD, for his thoughtful reflections regarding the contents of this article. The author also thanks the anonymous reviewers, whose comments were instrumental to improving earlier drafts of the manuscript.

\section{References}

1. Family Medicine for America's Health [homepage]. Available from: http://fmahealth.org/. Accessed September 28, 2015.

2. Oberlander J. Unraveling Obamacare-can Congress and the Supreme Court undo health care reform? N Engl J Med 2014;371:2445-7.

3. Ventres W, Kooienga S, Vuckovic N, Marlin R, Nygren P, Stewart V. Physicians, patients, and the electronic health record: an ethnographic analysis. Ann Fam Med 2006;4:124-31.

4. Cooke M, Irby DM, O'Brien BC. Educating physicians: a call for reform of medical school and residency. San Francisco (CA): Jossey-Bass/Carnegie Foundation for the Advancement of Teaching; 2010.

5. Starfield B, Shi L, Macinko J. Contribution of primary care to health systems and health. Milbank Q 2005;83:457-502.

6. Loxterkamp D. What matters in medicine: lessons from a life in primary care. Ann Arbor: University of Michigan Press; 2013.

7. Carmichael LP. The relational model: a paradigm of family medicine. J Fla Med Assoc 1980;67:860-2.

8. Ransom DC, Vandervoort HE. The development of family medicine. Problematic trends. JAMA 1973; 225:1098-102.

9. Barnett BL Jr. Between the lines: reflections of a family physician. Kansas City (MO): Society of Teachers of Family Medicine Foundation; 1989.

10. Stephens GG. Family medicine as counterculture. Fam Med 1989;21:103-9.

11. Kreitzer MJ, Kligler B, Meeker WC. Health professions education and integrative healthcare. Explore (NY) 2009;5:212-27.

12. Frist WH, Presley MK. Training the next generation of doctors in palliative care is the key to the new era of value-based care. Acad Med 2015;90:268-71.

13. Ventres WB. Family practice: on the cutting edge of medicine. Fam Med 1994;26:208-9.
14. Engel GL. The clinical application of the biopsychosocial model. Am J Psychiatry 1980;137:535-44.

15. Engel GL. The biopsychosocial model and family medicine. J Fam Pract 1983;16:409, 412-3.

16. Anandarajah G. The $3 \mathrm{H}$ and BMSEST models for spirituality in multicultural whole-person medicine. Ann Fam Med 2008;6:448-58.

17. Worby J. The family life cycle: an orienting concept for the family practice specialist. J Med Educ 1971; 46:198-203.

18. Timmermans S, Mauck A. The promises and pitfalls of evidence-based medicine. Health Aff (Millwood) 2005;24:18-28.

19. Woolley A, Kostopoulou O. Clinical intuition in family medicine: more than first impressions. Ann Fam Med 2013;11:60-6.

20. Braveman P, Gottlieb L. The social determinants of health: it's time to consider the causes of the causes. Public Health Rep 2014;129(Suppl 2):19-31.

21. Ventres WB, Haq CL. Toward a cultural consciousness of self-in-relationship: from "us and them" to "we." Fam Med 2014;46:691-5.

22. Scott JG, Cohen D, Dicicco-Bloom B, Miller WL, Stange KC, Crabtree BF. Understanding healing relationships in primary care. Ann Fam Med 2008; 6:315-22.

23. Ventres W, Dharamsi S. Beyond religion and spirituality: faith in the study and practice of medicine. Perspect Biol Med 2013;56:352-61.

24. Ventres WB. Educating our patients about life and the end of life: toward a pedagogy of dying. J Am Board Fam Med 2014;27:713-6.

25. Ventres W, Frankel R. Shared presence in physicianpatient communication: a graphic representation. Fam Syst Health 2015;33:270-9.

26. Frey JJ III, Ventres WB. "Voices from Family Medicine" Project. Leawood (KS): American Academy of Family Physicians Foundation; 2011. Available from: http://www.aafpfoundation.org/online/foundation/ home/programs/center-history/oralhistory/voicesfm. html. Accessed September 28, 2015.

27. Ventres WB. How I think: perspectives on process, people, politics, and presence. J Am Board Fam Med 2012;25:930-6.

28. Ventres W. The joy of family practice. Ann Fam Med 2012;10:264-8. 